\title{
MIGRAÇÃO POR SOBREVIVÊNCIA: SOLUÇÕES BRASILEIRAS
}

\author{
Mariana Almeida Silveira Corrêa ${ }^{1}$ \\ Raísa Barcellos Nepomuceno ${ }^{2}$ \\ Weslley H. C. Mattos ${ }^{3}$ \\ Carla Miranda ${ }^{4}$
}

\begin{abstract}
O trabalho pretende tratar do problema da delimitação e relevância da distinção entre duas modalidades de deslocamento humano que hoje são entendidas e compartilhadas por muitos Estados-nacionais modernos: os chamados migrantes econômicos e os refugiados. No entanto, é observado que entre essas duas categorias existe um grupo, o qual chamaremos de migrantes por sobrevivência não refugiados, baseando no conceito de Betts. O texto abordará a vulnerabilidade desse grupo e a necessidade de uma proteção internacional que os incorpore. Serão explicitados quatro casos em que o Brasil adotou posturas diferentes para cada um deles.
\end{abstract}

Palavras-chave: refúgio, migração por sobrevivência, migração forçada, fluxos mistos, direitos fundamentais, Regimes Internacionais.

Os fluxos de migração são frequentes no mundo desde os mais remotos tempos. No entanto, o volume de migrantes variou dependendo do período histórico, sendo a motivação para os deslocamentos muito diversa. Atualmente, as migrações são classificadas basicamente como forçadas ou espontâneas. Em geral, medidas de proteção são adotadas para aqueles que são oficialmente julgados pelos Estados como deslocados forçados, enquanto que os que são considerados

1 Graduada em Relações Internacionais, voluntária de Elegibilidade da Caritas Arquidiocesana Rio de Janeiro (CARJ), Laboratório de Refúgio e Migração (LIvRI), Rio de Janeiro, Brasil.

2 Graduanda em Relações Internacionais, voluntária de Elegibilidade da Caritas Arquidiocesana Rio de Janeiro (CARJ), Laboratório de Refúgio e Migração (LIvRI), Rio de Janeiro, Brasil.

3 Mestrando do Programa de Pós-Graduação em Ciências Sociais, PPCIS-UERJ, Laboratório de Refúgio e Migração (LlvRI), Rio de Janeiro, Brasil.

4 Advogada da Caritas Arquidiocesana Rio de Janeiro (CARJ), mestranda de Direitos Humanos e Democratização na E.MA European, Laboratório de Refúgio e Migração (LIvRI), Rio de Janeiro, Brasil. 
migrantes espontâneos devem procurar alternativas de regularização ou sofrem com medidas restritivas. Quem são aqueles que os Estados consideram migrantes forçados? E quem seriam os espontâneos?

A migração forçada pode ter várias origens ou causas, incluindo perseguição, violência, desastres ecológicos e ambientais. Para aqueles que fogem em razão de perseguições perpetradas em razão de nacionalidade ou por motivos políticos, dentre outros motivos, há previsão de proteção definida por instrumentos jurídicos internacionais. Os Estados signatários da Convenção de 1951 das Nações Unidas sobre o Estatuto do Refugiado assumem o compromisso de dar proteção às pessoas que são vítimas de perseguição, em razão de sua nacionalidade, raça (ou etnia), sexo, religião, grupo social ou opiniões políticas. Esta Convenção, assim como, o protocolo de 1967, foram criados visando proteger sobretudo os deslocados em razão da Segunda Guerra Mundial, mas mesmo antes a comunidade internacional havia estabelecido mecanismos de proteção em razão dos deslocamentos massivos na Rússia.

Dentro do contexto africano, em 1974, um grande número de nações convencionou estender o conceito de refugiado, através da Convenção da Organização de Unidade Africana (OUA) que Rege os Aspectos Específicos dos Problemas dos Refugiados em África, estabelecendo caráter vinculativo ao ser ratificada. Essa convenção foi criada com o objetivo de proteger os migrantes forçados que cresciam em grande número em virtude de inúmeros conflitos existentes, causados pelo fim da era colonial na África ${ }^{5}$.

O termo refugiado aplica-se também a qualquer pessoa que, devido a uma agressão, ocupação externa, dominação estrangeira ou a acontecimentos que perturbem gravemente a ordem pública numa parte ou na totalidade do seu país de origem ou do país de que tem nacionalidade, seja obrigada a deixar o lugar da residência habitual para procurar refúgio noutro lugar fora do seu país de origem ou de nacionalidade ${ }^{6}$.

Na América Latina, ocorreram encontros entre os países da região que culminaram na criação da Declaração de Cartagena em 1984. Esta pretendia atender a demanda da época, no momento, em que diversos países da América Central e o Chile passavam por ditaduras, nas quais houve vários conflitos armados que provocaram mais de 2 milhões deslocamentos para países da mesma região (América Latina), EUA e Canadá7.

${ }_{5}$ JUBILUT, Liliana Lyra; APOLINÁRIO, Silvia Menicucci. A necessidade de proteção internacional no âmbito da migração.

6 CONVENÇÃO da Organização de Unidade Africana Que Rege os Aspectos Específicos dos Problemas dos Refugiados em África, artigo 1ㅇinciso II.

7 ANDRADE, José Henrique Fischel de. Regional policy approaches and harmonization: a latin american perspective, p. 400 . 
(...) a definição ou o conceito de refugiado recomendável para sua utilização na região é o que, além de conter os elementos da Convenção de 1951 e do Protocolo de 1967, considere também como refugiados as pessoas que tenham fugido dos seus países porque a sua vida, segurança ou liberdade tenham sido ameaçadas pela violência generalizada, a agressão estrangeira, os conflitos internos, a violação maciça dos direitos humanos ou outras circunstâncias que tenham perturbado gravemente a ordem pública ${ }^{8}$.

No entanto, diferente da Convenção da OUA, a Declaração possuiu caráter meramente recomendatório e pretendia expandir a definição de refugiado. Ela obteve forte adesão ao ser incluída na legislação de 14 países da região ${ }^{9}$.

A Lei brasileira 9.474 de 1997 foi criada sob o espírito da Declaração de Cartagena. Além de reconhecer como refugiado os que sofrem perseguição, seja ela por motivos de raça, opinião política, religião grupo social ou nacionalidade, a Lei reconhece como refugiados todos aqueles que se encontravam em um território marcado por situação de grave generalizada violação dos Direitos Humanos.

Art. 10 Será reconhecido como refugiado todo indivíduo que:

I - devido a fundados temores de perseguição por motivos de raça, religião, nacionalidade, grupo social ou opiniões políticas encontre-se fora de seu país de nacionalidade e não possa ou não queira acolher-se à proteção de tal país;

II - não tendo nacionalidade e estando fora do país onde antes teve sua residência habitual, não possa ou não queira regressar a ele, em função das circunstâncias descritas no inciso anterior;

III - devido a grave e generalizada violação de direitos humanos, é obrigado a deixar seu país de nacionalidade para buscar refúgio em outro país ${ }^{10}$.

O inciso III do artigo $1^{\circ}$ da lei 9.474/97 prevê proteção para os deslocados de regiões de conflito, os quais não necessariamente sofrem uma perseguição, mas sofrem, por exemplo, com a violência ou ameaça de violência em razão da existência ou aproximação de grupos que devastam cidades, até mesmo, exterminam populações. O caso dos congoleses de algumas regiões da República Democrática do Congo, como os Kivus, ou os Sírios são exemplos de aplicação do inciso III. Os congoleses dessas regiões são obrigados a migrar, devido à ação de grupos rebeldes que praticam ações extremamente violentas, como assassinatos, sequestros, estupros massivos, pilhagens, dentre outras. Os sírios sofrem com bombardeios constantes em decorrência do intenso conflito existente no país. Nesses casos é fácil constatar a grave e generalizada violação dos Direitos Humanos nestas regiões. Adiante, trataremos destes casos mais detalhadamente.

${ }_{8}$ DECLARAÇÃO de Cartagena sobre os Refugiados, Conclusões e recomendações III Terceira.

9 ACNUR. Trinta anos após Declaração de Cartagena para os Refugiados, ONU inicia consulta sobre o tema.

${ }^{10}$ BRASIL. Lei 9.474 de 22 de julho de 1997. 
Todavia, podemos observar que existem fluxos migratórios que não se enquadram em nenhuma das definições estabelecidas pela lei brasileira de refúgio e que, no entanto, se enquadram na definição de migração forçada. Como classificar esses migrantes que não são nem considerados refugiados nem migrantes econômicos? As autoridades brasileiras, assim como, outros países, os classificam de migrantes econômicos e somente os haitianos receberam um visto por razões humanitárias. Contudo, essa classificação não define exatamente sua situação, já que migrantes econômicos são fluxos espontâneos. Logo, esse grupo de pessoas estaria entre a dicotomia de refugiados e migrantes econômicos. O caso dos ganeses que chegam ao Brasil são exemplos deste tipo de migração.

$\mathrm{O}$ autor Alexander Betts ${ }^{11}$ discorre sobre essa temática e cria o termo migrantes por sobrevivência ${ }^{12}$ para classificar novos fluxos de migração forçada que necessitam de proteção internacional, mas que estão excluídos do instituto do Refúgio. Neste artigo, será explicitado quem são esses migrantes por sobrevivência, quais são as suas necessidades e razões para se deslocar, conforme a opinião de Betts. Ainda, serão mencionadas a vulnerabilidade e ausência de um instituto de proteção para este grupo, que cai num vácuo entre migrantes econômicos e refugiados. O fluxo de ganeses para o Brasil será utilizado como estudo de caso para exemplificar os migrantes por sobrevivência, enquanto os congoleses e os sírios serão apresentados como casos clássicos de reconhecimento de refúgio e, por fim, os haitianos serão o exemplo em que o governo brasileiro adotou uma medida ad hoc para proteger um grupo vulnerável, sem conceder o status de refugiado. A República Democrática do Congo, a Síria e o Haiti serão tratadas neste artigo para efeitos comparativos com o grupo de migrantes por sobrevivência que não recebem nenhuma proteção do governo.

\section{Migração por sobrevivência}

O autor Alexander Betts discute acerca do tema de fluxos mistos em seu texto Survival Migration. Primeiramente, ele trata da definição de refugiado na Convenção de 1951, na qual a proteção era baseada na perseguição individual. Após disso, comenta a respeito da Declaração de Cartagena na América Latina e da Convenção da Organização de Unidade Africana que Rege os Aspectos Específicos dos Problemas dos Refugiados em África que, igualmente, reconhecem como refugiados pessoas que se deslocam em decorrência de violência generalizada e desordem pública. Em seguida, afirma que os instrumentos atuais de proteção à migração forçada não atendem aos novos deslocamentos. O autor relata que a interação da combinação de desastres ambientais, Estados frágeis e a ausência

\footnotetext{
11 BETTS, Alexander. Survival Migration: A New Framework, p. 361-382.

12 A expressão original na língua inglesa é survival migrants.
} 
de subsistência culminam na necessidade de proteção por parte da comunidade internacional. Contudo, esses atores estão fora da proteção estabelecida pelas convenções e declarações internacionais acerca do refúgio, por isso, muitos países tendem a classificá-los como migrantes econômicos. Todavia, não o são, pois o deslocamento não é voluntário. Logo, Betts afirma que esses atores estão entre a dicotomia migrante econômico e refugiado ${ }^{13}$.

Assim, no contexto de mudança climática, dentro do debate acerca dos "deslocados ambientais", surge a questão sobre a necessidade de reconhecimento de novas formas de deslocamento, demandando a ampliação do conceito de refugiado ou a criação de mecanismos complementares de proteção. O autor destaca que os chamados "deslocamentos ambientais" não ocorrem somente pela alteração do clima ou por desastres naturais, pois esse fenômeno não é monocausal, mas vem acompanhado de outros fatores, como falta de subsistência e Estado frágil, incidindo em uma conjuntura, onde há um vácuo institucional ${ }^{14}$.

Alexander Betts utiliza o conceito de migração por sobrevivência para abranger esses novos atores, que são definidos como "pessoas que estão fora de seu país de origem em virtude de uma ameaça real à sua existência, não tendo acesso a uma solução ou reparação dentro do próprio país"15. Esta definição nos traz três elementos chave (i) estar fora de seu país de origem; (ii) ameaça à sua existência; e (iii) falta de acesso a uma solução ou reparação doméstica. Os primeiro e terceiro elementos não parecem ser difíceis de entender: estar fora de seu país de origem quer dizer que a pessoa demanda proteção à comunidade internacional por não ter acesso a soluções ou reparações domésticas.

A definição de Betts é similar ao inciso I do artigo primeiro da lei do refúgio 9.474/97: "devido a fundados temores de perseguição por motivos de raça, religião, nacionalidade, grupo social ou opiniões políticas encontre-se fora de seu país de nacionalidade e não possa ou não queira acolher-se à proteção de tal país". O "encontra-se fora do seu país de origem" assemelha-se a "estão fora de seu país de origem", e o "e não possa ou não queira acolher-se à proteção de tal país" é semelhante a "não tendo acesso a uma solução ou reparação dentro do próprio país". Porém, enquanto na Lei Brasileira de Refúgio é usada a definição "fundado temor de perseguição", Alexandre Betts usa "ameaça real à sua existência", isso porque a Lei brasileira foca somente causas como perseguição ou violação de direitos, uma vez que todo perseguido tem sua existência ameaçada, mas nem toda pessoa que tem sua existência ameaçada é perseguida. A similaridade entre a lei brasileira e o conceito de Betts ocorre porque

${ }^{13}$ BETTS, op. cit.

14 Ibidem.

15 Tradução livre de "persons outside their country of origin because of an existential threat to which they have no access to a domestic remedy or resolution". 
ambos tratam da proteção que indivíduos obrigados a migrar devem receber. Alexander Betts, neste raciocínio, afirma que todo refugiado pelas convenções internacionais é um migrante por sobrevivência, porém nem todo migrante por sobrevivência é um refugiado, assim como, todo migrante por sobrevivência é um migrante internacional, porém nem todo migrante internacional é um migrante por sobrevivência ${ }^{16}$. O autor mostra o seguinte diagrama:

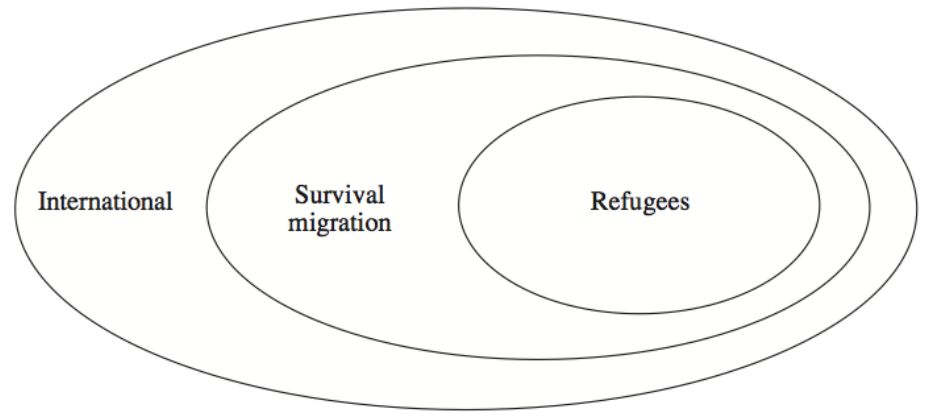

Figura 1: Diagrama Mostrando a Relação Conceitual entre Migrante por Sobrevivência, Refugiados e Migrante Internacional ${ }^{17}$

O conceito de migrante por sobrevivência, também, pode acolher aqueles que vivem em uma situação de privação ou restrição de determinados direitos fundamentais em seu país de origem e que, por isso, precisam buscar esses direitos em outro país. Betts fundamenta seu conceito utilizando o termo direito básico de Henry Shue que foi aplicado à esfera do refúgio por Andrew Shacknove. Este termo pode ser definido como o direito sem o qual nenhum outro pode ser desfrutado. Assim sendo, existem três tipos de direitos básicos: liberdade básica, segurança básica e subsistência básica. O autor chama atenção para o fato de que a definição de refugiado se foca na segurança básica, às vezes, se estendendo à liberdade básica, porém excluindo a subsistência básica.

Betts, ainda, discorre a respeito de inúmeras jurisprudências que surgiram da Convenção Europeia de Direitos Humanos (CEDH), Convenção Americana sobre Direitos Humanos (CADH) e Convenção contra Tortura (CAT) que tentam proteger aqueles excluídos pelas convenções do refúgio, porém incluídos pelas demais convenções citadas. No entanto, a CAT, CEDH e CADH apresentam escopo e aplicação restritos às necessidades dos migrantes por sobrevivência não refugiados, pois estão limitados quanto à garantia do direito à vida, a não sofrer tortura e tratamento desumano e degradante. Além disso, as jurisprudências

\footnotetext{
16 BETTS, op. cit., p. 365.

17 Ibidem, p. 366.
} 
costumam vir do CADH e CEDH provenientes das Américas e da Europa, dificilmente se aplicando à África, de onde provém a maioria desses fluxos. Por fim, estas convenções não garantem direitos econômicos e sociais, excluindo a maioria dos migrantes por sobrevivência não refugiados ${ }^{18}$.

Alexander Betts afirma que, devido à ausência de instrumentos internacionais que definam uma proteção aos novos atores e o fato destes permanecerem em deslocamento, atravessando as fronteiras para diversos países, cada Estado hospedeiro define suas próprias soluções para essas pessoas. A carência de mecanismos permite que os países disponham de poder discricionário para a tomada de decisão em relação a esses deslocados. Assim, as decisões tanto nacionais como internacionais acabam apresentando mais um cunho político do que normativo legal.

$\mathrm{O}$ autor mostra alguns exemplos de decisões diversas tomadas por um determinado país em relação a um fluxo migratório, como, por exemplo, o caso da Angola que violou sistematicamente os direitos humanos, perpetuando abusos contra os migrantes provenientes da República Democrática do Congo. O Quênia, por exemplo, realizou reconhecimento prima facie de todos os procedentes da Somália, que porém receberam direitos limitados. Na África do Sul, por sua vez, deram uma resposta ad hoc aos originários do Zimbabwe, mas estes não obtiveram status formal e sofrem com a ausência de direitos econômicos e sociais ${ }^{19}$. O Brasil apresentou respostas diferentes para fluxos variados: os haitianos receberam visto humanitário, uma medida oficial ad hoc, enquanto os sírios foram reconhecidos prima facie como refugiados; os congoleses têm seus pedidos de refúgio analisados caso a caso e, por outro lado, os senegaleses, em sua maioria, são considerados migrantes econômicos. Essas diferentes respostas a cada fluxo migratório, sucedidas em vários países, também, estão presentes no Brasil e serão discutidas neste artigo mais adiante.

Por fim, Betts analisa a modificação do conceito refugiado na América Latina e África, a qual permite perceber que ele foi ampliado de acordo com a necessidade de cada contexto histórico que visava proteger os fluxos emergentes de migração forçada nos respectivos cenários. No entanto, Betts propõe que ao invés de alterar o estatuto do refúgio ou criar normas fixas as quais incorporem os novos fluxos de migração forçada carentes de proteção, haja um regime flexível. Esta ideia de flexibilização de regime ${ }^{20}$ surge como um importante recurso para tal ao elucidar que regimes internacionais - normas, regras, princípios, procedimentos governamentais de tomada de decisões, etc. - não são entidades que estão fixas e estáticas no papel. São, na verdade, dinâmicas e

\footnotetext{
18 Ibidem, p. 364-365.

19 Ibidem, p. 375-376.

20 Tradução livre para "Regime Stretching".
} 
adaptáveis e devem variar de acordo com o local e as manifestações nacionais, que, frequentemente, divergem do regime de escopo global ${ }^{21}$. Sobre isto, o autor pode constatar que houve situações em que o regime não foi flexibilizado e as lacunas contundentes ocasionaram significantes consequências humanas, como a ocorrida em Angola com os congoleses ${ }^{22}$.

\section{Casos Clássicos de Refúgio}

Nesta seção serão expostos os casos considerados como clássicos de refúgio no Brasil, ou seja, aqueles que estão previstos na lei brasileira 9.474/97 e estão em conformidade com a Convenção de 1951, Protocolo de 1967 e Declaração de Cartagena. Serão utilizados exemplos de dois países em que o Brasil adotou posturas diferentes frente às solicitações. Primeiramente, os pedidos congoleses que são avaliados individualmente, caso a caso, como acontece com a maioria das demais solicitações. Depois, será apresentado o caso dos sírios, para o qual o Brasil adotou a medida de reconhecimento prima facie.

\subsection{Congoleses}

República Democrática do Congo (RDC) é o país que apresenta maior quantidade de solicitações de refúgio no Rio de Janeiro e o segundo com maior número de casos reconhecidos no Brasil em 2013, ficando atrás somente da Síria. Apesar de ser o terceiro ano seguido que o país se mantém em segundo lugar em relação ao número de refugiados reconhecidos, somente $52 \%$ dos solicitantes receberam o reconhecimento em 2013, totalizando 106 casos $^{23}$.

Os congoleses passam pelo processo de solicitação de refúgio regular no Brasil e seus pedidos são avaliados caso a caso. Essas pessoas chegam aqui das mais diversas formas, seja legalmente de avião ou até mesmo clandestinamente em barcos. Cada indivíduo ou família chega da forma que é possível. Todavia, o Brasil não é o único destino desta nação. A diáspora congolesa está espalhada por diversos países. Segundo o ACNUR, em janeiro de 2014 havia cerca de 500.000 refugiados e 64.000 solicitantes de refúgio de origem congolesa no mundo e quase 3 milhões de deslocados internos (IDPs) no país ${ }^{24}$. Conforme a The Refugee Project, a proporção de refugiados congoleses é 1 para 129 habitantes em 2012. Os refugiados congoleses estão presentes em 76 países, principalmente em Ruanda, Burundi, Uganda e Tanzânia. O Reino Unido é o primeiro país de acolhida não africano, com 3.311 refugiados. Conforme o ACNUR, até setembro de 2014 havia no Brasil 571 refugiados congoleses.

\footnotetext{
${ }^{21}$ BETTS, op. cit., p. 363.

22 Ibidem, p. 375-376.

23 ACNUR. Refúgio no Brasil: uma análise estatística (2010-2013).

${ }^{24}$ ACNUR. Global Appeal 2014-2015.
} 
A República Democrática do Congo enfrentou duas guerras e vive até hoje em profunda instabilidade política e humanitária. $\mathrm{O}$ atual presidente Kabila, foi eleito em 2006, em um processo considerado fraudulento por atores internacionais e nacionais. Ele governa o país com autoritarismo reprimindo fortemente seus opositores. Relatórios de organismos internacionais condenam o governo por diversas medidas violadoras dos Direitos Humanos, que acontecem inclusive, em Kinshasa, capital do país. Muitas regiões da RDC vivem em completa instabilidade, apresentando conflitos frequentes, devido à presença ou domínio de grupos rebeldes, como é o caso dos territórios de Kivu Norte, Kivu Sul, Katanga, Maniema e Província Oriental ${ }^{25}$, as mais afetadas por esse fenômeno.

Os grupos rebeldes nesse país são das mais diversas naturezas, porém suas práticas de violência são parecidas. Pilhagem de casas, sequestros, estupro em massa, e assassinato são as principais formas de ataques desses grupos que objetivam instabilizar e dominar a região e a população. Em Katanga, por exemplo, existe uma região conhecida como triângulo da morte, na qual os grupos Mai Mai Katanga ${ }^{26}$ e Mai Mai Gedeon ${ }^{27}$ atuam intensamente. Enquanto que na Província Oriental, principalmente em Dungu ${ }^{28}$ e Faradje ${ }^{29}$, o LRA (Lord's Resistance Army) é responsável por incontáveis ataques na região. O medo provoca os deslocamentos humanos, que dão o caráter catastrófico aos números acima mencionados.

Os congoleses provenientes destas regiões de total instabilidade são reconhecidos como refugiados de acordo com o inciso III do artigo $1^{\circ}$ da Lei 9.474/97, em razão da "grave e generalizada violação dos direitos humanos"30. Enquanto que os oriundos de Kinshasa, normalmente, se encaixam no inciso I do mesmo artigo, porque são vítimas de perseguição individual, em razão de sua atuação política, mas também em razão de filiação religiosa ou pertencimento a um determinado grupo social, ou ainda, em razão da combinação de mais de uma causa.

Todavia, apesar de quase todas as solicitações apresentarem elementos que as enquadrem no inciso I ou III, apenas 52\% foram reconhecidas em 2013. Em 2012, a porcentagem foi similar: 53\%. Nos anos anteriores, foi ainda menor, $38 \%$ em 2011 e $32 \%$ em $2010^{31}$.

\footnotetext{
${ }^{25}$ NORWEGIAN REFUGEE COUNCIL/INTERNAL DISPLACEMENT MONITORING CENTRE - NRC/ IDMC. Global Overview 2014: people internally displaced by conflict and violence - Democratic Republic of the Congo.

${ }^{26}$ INTEGRATED REGIONAL INFORMATION NETWORKS - IRIN. Conflict cuts off civilians in DRC's Katanga.

${ }^{27}$ ONU. Conferência de Imprensa das Nações Unidas de 22 de janeiro.

${ }^{28}$ COUNTRY of Origin Research and Information - CORI. CORI Country Report Democratic Republic of Congo: Security Issues, de Abril de 2013.

${ }^{29}$ UN Security Council. Report of the Secretary-General on the activities of the United Nations Regional Office for Central Africa and on the Lordis Resistance Army-affected areas.

${ }^{30}$ BRASIL. Lei 9.474/97 art.1 inciso III.

31 ACNUR. Refúgio no Brasil..., op. cit.
} 


\subsection{Sírios}

A onda de violência na Síria teve início em 2011 e, desde então a situação vem se deteriorando. Segundo informações da ONU 32 sobre o ano de 2014, 6.8 milhões de Sírios demandam assistência humanitária e são em sua maioria deslocados internos. A assistência a deslocados internos pelo ACNUR e por outras agências humanitárias se torna muito difícil dado o clima de insegurança e instabilidade do país.

O país é dividido tanto politicamente quanto religiosamente e passa por uma dura guerra civil. No país ocorrem crimes de guerra e a população perde o acesso aos serviços mais básicos como água e eletricidade. Segundo relatório de 2014 do Human Rights Watch ${ }^{33}, 32$ dos 88 hospitais públicos do país fecharam e centenas de trabalhadores da área de saúde e pacientes foram presos, torturados e mortos. Cluster bombs continuam sendo usadas, mesmo sendo armas proibidas pela "2008 Convention on Cluster Bombs", da qual a Síria não é signatária. Ademais, foram registrados, em agosto de 2013, ataques com armas químicas, que mataram centenas de mulheres e crianças nas proximidades de Damasco.

Diante dessa situação na Síria e do alto número de deslocados e refugiados, o governo brasileiro tem reconhecido prima facie os sírios que procuram proteção internacional no Brasil, apesar de esse reconhecimento prima facie ser uma prática do CONARE ainda não regulada por uma resolução.

\section{Caso com solução ad hoc}

Nesta seção será apresentado o caso do Haiti, cujos nacionais não receberam reconhecimento de refúgio. No entanto, o governo brasileiro, entendendo a necessidade de conceder proteção a estes indivíduos, adotou uma medida ad hoc para resguardá-los. Este caso se assemelha com a solução tomada pela África do Sul em relação ao fluxo de Zimbabuanos.

\subsection{Haiti}

O Haiti passa por uma situação muito delicada que já se estende por longos anos. Situação essa que envolve fragilidade e instabilidade política, conflitos armados e desastres naturais. Quatro anos após o último terremoto, ainda há pessoas morando em acampamentos e a desnutrição no país é muito elevada. Já antes do terremoto, a situação do setor de saúde no país era uma das mais frágeis da região, enfrentando também uma séria crise de cólera que matou milhares de pessoas. Em 2010 o terremoto matou mais de 150.000 pessoas, criando uma situação de caos, uma das maiores catástrofes do continente.

\footnotetext{
32 ACNUR. Global Appeal..., op. cit.

33 HUMAN RIGHTS WATCH. World Report 2014.
} 
Ao falar de Haiti, levantamos a questão dos Refugiados Ambientais. Em uma crise humanitária por razões ambientais, em que o Estado não tem condições de gerir a crise, a ajuda internacional se faz necessária. De acordo com informações da Agência da ONU para refugiados, em 2014 ainda há cerca de 280 mil deslocados internos (IDPs) que permanecem em campos e outras 200 mil pessoas vivendo em assentamentos ou de favor em casas de famílias ${ }^{34}$. Frente a essa situação, milhares de haitianos decidem deixar seu país.

As complicações dessa migração já começam no Haiti. Haitianos relatam que para conseguir o visto humanitário em seu país precisam pagar taxas a atravessadores. Eles não têm acesso a informações sobre os vistos e há denúncias ainda não confirmadas sobre esquemas de propinas. Ao chegarem ao Brasil, encontram uma situação parecida com a pós terremoto em seu país em 2010: abrigos de primeira acolhida lotados em condições de higiene precária. Após o fechamento do abrigo no Estado do Acre no município de Brasileia, passaram a migrar para outros Estados do país, principalmente para o sul e São Paulo.

O Comitê Nacional para Refugiados (CONARE) não tem encontrado base legal na lei de refúgio brasileira para garantir proteção aos haitianos. Então de acordo com a Resolução no 8/06 do Conselho Nacional de Imigração, eles receberam uma solução excepcional, geralmente adotada para os casos que precisam de proteção humanitária.

A concessão dos vistos humanitários para os haitianos está fundamentada na Resolução 97 de janeiro de 2012 e com validade até janeiro de 2014; em outubro de 2013, foi estendida até janeiro de 2015. Paulo Sérgio de Almeida, presidente do Conselho Nacional de Imigração (CNIg), destacou a necessidade de proteção humanitária ainda que essa seria uma forma de evitar a entrada ilegal de haitianos por fronteiras terrestres. À luz de Betts, podemos entender o caso dos haitianos como um daqueles que demandam proteção internacional adequada, independentemente do mecanismo tradicional do refúgio.

É bom destacar que o visto humanitário não garante a proteção internacional prevista pela Convenção de 1951: o "non refoulement". Isso significa que os haitianos não estão protegidos do retorno forçado ao seu país de origem.

\section{Caso Migração por Sobrevivência não refugiado}

Nessa seção será discutido o caso dos ganeses que não são considerados refugiados pelo governo brasileiro e não receberam nenhuma proteção ad hoc pelo mesmo. Os ganeses podem ser considerados como migrantes por sobrevivência não refugiado, segundo o conceito adotado por Betts.

\footnotetext{
${ }^{34}$ ACNUR. 2014 UNHCR regional operations profile - North America and the Caribbean.
} 


\subsection{Gana}

O fluxo de migrantes recebidos pelo Brasil nos últimos anos em grande parte é proveniente do continente africano, lugar onde há historicamente diversos tipos de perseguição e conflitos. Contudo, se basear somente nessa concepção canônica de violações flagrantes não comporta de modo desejável toda a complexidade e variedade de contextos nacionais que motivam esses novos fluxos migratórios que chegam ao Brasil.

O fluxo de ganeses exemplifica o caso dos migrantes por sobrevivência definido por Betts. Gana é um país onde há grandes fluxos migratórios e essa migração intensa nos últimos anos não mereceu uma proteção internacional adequada. Assim, este caso nos provoca a pensar sobre o problema da delimitação e relevância da distinção clássica entre migrante econômico e refugiado.

A partir dessa nova configuração do fenômeno do deslocamento humano no contexto moderno de globalização, a crítica aos conceitos rígidos do migrante considerado refugiado e do migrante considerado econômico se faz necessária.

No relatório sobre Desenvolvimento Humano feita pelas Nações Unidas, que enfatiza o maior crescimento do IDH nos países do sul, Gana apresenta um índice de desenvolvimento humano médio ${ }^{35}$. Em comparação com outros países africanos, Gana apareceria em uma condição razoável, mas isso não garante a eficácia do Estado em promover os direitos básicos com equidade, incluindo segurança, liberdade e subsistência.

Gana apresenta bons números em diversos índices, em relação aos países africanos, no relatório de desenvolvimento humano de $2013^{36}$. Todavia, se comparado, por exemplo, com a América do Sul esses números são extremamente baixos. Além disso, é possível observar um grande fluxo de deslocados a partir de 1994. Segundo The Refugee Project, cerca de 14.000 ganeses foram reconhecidos refugiados em 15 países diferentes, sendo que este número variou muito até 2009. Desde esse ano até 2012, só houve aumento na quantidade de refugiados de Gana, alcançando mais de 24.000 em 47 Estados distintos em 2012. Os três países mais receptores de refugiados ganeses, em 2012, foram: Togo, Alemanha e Itália. Cabe ressaltar que esses números referem-se a refugiados, logo, são desconsiderados os demais migrantes por sobrevivência não refugiados.

Outro fenômeno recorrente em Gana é o tráfico de pessoas. Este país é destino, trânsito e exportador de indivíduos que sofrem com o tráfico internacional de pessoas. Diversos relatórios ressaltam esta prática no país: inúmeras pessoas são aliciadas a sair do país com propostas de condições de

\footnotetext{
35 UN Development Programme. Human Development Report 2013 - The Rise of the South: Human Progress in a Diverse World.

${ }^{36}$ Ibidem.
} 
vida melhor no exterior e se tornam vítimas do trabalho escravo em outros Estados. Ademais, indivíduos de outros países africanos são iludidos com falsas propostas de emprego em Gana e quando chegam ao país de destino são vítimas do trabalho forçado. Algumas pessoas sofrem dentro do próprio país essa exploração, principalmente nas regiões perto da produção de petróleo. Essa situação exprime a grande vulnerabilidade em que essas pessoas se encontram, não só por sofrerem com o trabalho forçado, mas, também, por serem fáceis alvos de aliciamento para o tráfico internacional de pessoas ${ }^{37}$.

O conceito de migrante por sobrevivência garante que dimensões importantes não colocadas em relevo sejam valorizadas para servirem de parâmetro para o alargamento da proteção internacional. Ganeses e outros contingentes de pessoas de outras nacionalidades, então, não ficariam no impasse de serem ou não reconhecidos como dignos de uma proteção internacional adequada. Teriam direito a proteção internacional pelo fato de serem migrantes por sobrevivência.

\section{Conclusão}

Neste artigo, tratamos dos casos de migração de quatro países em relação aos quais o Brasil adotou medidas distintas. Casos de dois países respectivamente a Síria e a República Democrática do Congo - cujos nacionais, em decorrência da lei brasileira 9.474/97, recebiam ou tinham a possibilidade de receber o reconhecimento de refúgio. Os outros dois casos, Haiti e Gana, não foram enquadrados no instituto do refúgio. Logo os nacionais de ambos os países não puderam ser reconhecidos como refugiados. No entanto, o governo brasileiro entendeu a necessidade de proteger os oriundos do Haiti, em razão da falta de proteção nacional. Dessa forma, o Brasil utilizou um expediente ad hoc, concedendo a residência por razões humanitárias, em vez de considerá-los refugiados. Em relação aos indivíduos de outros países que se encontrassem em situação semelhante à dos haitianos, ou seja, em situação de migração forçada não amparada pela lei Brasileira do Refúgio de 1997, como é o caso dos ganeses, mas também de senegaleses, bengalis, angolanos, guineenses, não houve a mesma solução.

A abordagem de Betts foi importante para entendermos que os Estados não possuem ou não querem se valer de mecanismos que resguardem todas as migrações forçadas, preferindo, em vez disso, classificar apenas alguns destes deslocamentos como forçados, nomeando outros como espontâneos. Com base na teoria de Betts, procuramos problematizar a distinção entre migrantes e refugiados e a relação de causalidade entre a situação social e/ou política no

${ }^{37}$ UNITED STATES DEPARTMENT OF STATE. 2014 Trafficking in Persons Report - Ghana. 
país de origem e a fuga. No caso dos refugiados, a relação é determinada pela involuntariedade da fuga e o "fundado temor de perseguição" como causa, assim como a grave e generalizada violação de direitos humanos. O critério é que a pessoa seja vítima de violência iminente, que os bens jurídicos "vida, integridade física, segurança ou liberdade" estejam em risco. Em relação aos migrantes, em geral, se afirma que, ao contrário dos refugiados, sua fuga é voluntária. Porém, refugiados também fogem voluntariamente e muitos migrantes vêem na fuga sua única opção de sobrevivência. Tratando-se de migrantes econômicos, a causa da miséria, em geral apresentada como algo "natural ou espontâneo", também poderia ser buscada em outras relações, incluindo ingerência externa, conflitos transnacionais, políticas econômicas internacionais seletivas, formas variadas de opressão e violência. A pobreza precisa ser problematizada e pode, muitas vezes, ser vista como uma questão de decisão política, de produção de violência e desigualdade, dentro de um contexto das relações internacionais.

Além disso, quando surgem dentro de seus territórios grandes fluxos migratórios não incluídos no instituto do refúgio, o Estado muitas vezes opta discricionariamente por uma medida precária ou ad hoc. Dessa forma, aqueles que, segundo Betts, são chamados de migrantes por sobrevivência, ficam extremamente vulneráveis. $\mathrm{O}$ autor indica, ainda, a possibilidade da adoção de um regime flexível que comporte as demandas atuais de migração forçada e os possíveis novos fluxos, já que estes tendem a mudar ao longo do tempo, apresentando motivos diversos para o deslocamento. É recordado que isso ocorreu nas Américas e na África, em que a Convenção de 1951, assim como o Protocolo de 1967, já não eram suficientes para as demandas da época, determinando, então, a ampliação do conceito de refúgio em ambas as regiões.

Este artigo se propôs a expor que os regimes atuais de proteção são ineficazes quanto ao amparo de todos os fluxos de migração forçada os migrantes por sobrevivência. A questão se esses indivíduos são refugiados, se deveriam ser entendidos como tal ou se deveria ser expandido o instituto do refúgio, como ocorreu em outros tempos, é controversa. A criação de novos regimes de proteção rígidos ou um flexível, como o proposto por Betts, seria, eventualmente, uma opção. No entanto, o fundamental é que alguma medida eficaz seja acolhida pela comunidade internacional, pois esses migrantes não podem ficar à deriva, vulneráveis, expostos à exploração, à degradação, à violência e, até mesmo, à ausência das mínimas condições de sobrevivência.

\section{Bibliografia}

ACNUR. Global Appeal 2014-2015. Disponível em: <http://www.unhcr.org/ga14/ index.xml>. Acesso em: 29.08.2014.

ACNUR. Trinta anos após Declaração de Cartagena para os Refugiados: ONU inicia 
consulta sobre o tema. 2014. Disponível em: < http://www.onu.org.br/trinta-anosapos-declaracao-de-cartagena-para-os-refugiados-onu-inicia-consulta-sobre-otema/>. Acesso em: 23.08.2014.

ACNUR. Refúgio no Brasil: uma análise estatística (2010-2013). Disponível em: < http:// www.acnur.org/t3/fileadmin/scripts/doc.php?file=t3/fileadmin/Documentos/ portugues/Estatisticas/Refugio_no_Brasil_2010_>. Acesso em: 23.08.2014.

ACNUR. 2014 UNHCR regional operations profile - North America and the Caribbean. Disponível em: <http://www.unhcr.org/cgi-bin/texis/vtx/ page page $=49 \mathrm{e} 491766 \&$ submit $=\mathrm{GO}>$. Acesso em: 23.08.2014.

ANDRADE, José Henrique Fischel de. Regional policy approaches and harmonization: a Latin American perspective. International Journal of Refugee Law, Oxford, v. 10, n. 3, 1998, p. 389-409.

BETTS, Alexander. Survival Migration: A New Framewor. Global Governance, v. 16, 2010, p. 361-382.

BRASIL. Lei 9.474 de 1997.

CONVENÇÃO da Organização de Unidade Africana que Rege os Aspectos Específicos dos Problemas dos Refugiados em África, 1974.

COUNTRY of Origin Research and Information. CORI Country Report Democratic Republic of Congo: Security Issues. April 2013. Disponível em: <http://www. refworld.org/docid/51fb97dd9.html>. Acesso em: 30.07.2014.

DECLARAÇÃO de Cartagena sobre os Refugiados de 1984. In IMDH; ACNUR (eds.). Lei 9474/97 e Coletânea de Instrumentos de Proteção Internacional dos Refugiados. Brasília: ACNUR/IMDH, 2005.

HUMAN RIGHTS WATCH. DR Congo: Army, UN Failed to Stop Massacre. HRW, 2014. Disponível em: <http://www.refworld.org/docid/53b6822c4.html>. Acesso em: 29.08.2014.

HUMAN RIGHTS WATCH. World Report 2014: events of 2013. Disponível em: http:// www.hrw.org/sites/default/files/wr2014_web_0.pdf. Acesso em: 29.08.2014.

INTEGRATED REGIONAL INFORMATION NETWORKS - IRIN. "Conflict cuts off civilians in DRC's Katanga". 2 de maio 2013. Disponível em: <http://www. refworld.org/docid/5187a4cb4.html>. Acesso em: 10.04.2014.

JUBILUT, Liliana Lyra; APOLINÁRIO, Silvia Menicucci. A necessidade de proteção internacional no âmbito da migração. 2010. Disponível em: <http://dx.doi. org/10.1590/S1808-24322010000100013 > . Acesso em: 23.08.2014.

NORWEGIAN REFUGEE COUNCIL/INTERNAL DISPLACEMENT MONITORING CENTRE (NRC/IDMC). Global Overview 2014: people internally displaced by conflict and violence - Democratic Republic of the Congo. 14 de maio de 2014. Disponível: $<$ http://www.refworld.org/docid/5374748614.html. Acesso em: 29.08.2014.

ONU. Conferência de Imprensa das Nações Unidas de 22 de janeiro. Disponível em: <http://radiookapi.net/files/Verbatim-22-Janvier-2014-FINAL.pdf>. Acesso em: 14.08.2014.

THE REFUGEE PROJECT. Disponível em: <http://www.therefugeeproject.org/\#/ 
2012/COD>. Acesso em: 29.08.2014.

UNDP. Human Development Report 2013 - The Rise of the South: Human Progress in a Diverse World. 19 de março de 2013. Disponível em: < http://www.refworld. org/docid/514850672.html>. Acesso em: 30.08.2014.

UNITED STATES DEPARTMENT OF STATE. 2014 Trafficking in Persons Report: Ghana. 20 de junho de 2014. Disponível em: <http://www.refworld.org/ docid/53ad1da44.html>. Acesso em: 29.08.2014.

UN Security Council. Report of the Secretary-General on the activities of the United Nations Regional Office for Central Africa and on the Lordis Resistance Army: affected áreas. 20 de maio de 2013, S/2013/297. Disponível em: < http://www. refworld.org/docid/51b6d7524.html>. Acesso em: 04.08.2014.

\section{Abstract}

\section{Survival Migration: Brazilian Solutions}

The following article aims to address the problem of the delimitation and relevance of the distinction between two types of human displacement that are understood and shared by many modern national States: called economic migrants and refugees. However, it is observed that between these two categories there is a group, which will call for survival migrants not refugees, based on the Betts concept. The text will talk about the group's vulnerability and the need of international protection that incorporates them. It will show four cases in which Brazil has adopted different postures for each of them.

Keywords: refuge, forced migration, survival migration, mixed flows, fundamental rights, international regimes.

Recebido para publicação em 31/08/2014.

Aceito para publicação em 15/02/2015.

Received for publication on August, 31 ${ }^{\text {th }}, 2014$. Accepted for publication on February, 15 $5^{\text {th }}, 2015$.

ISSN impresso: 1980-8585

ISSN eletrônico: 2237-9843

www. http://dx.doi.org/10.1590/1980-85852503880004414 